\title{
Os Médicos e a Gestão
}

\author{
Doctors and Management
}

\author{
Manuel DELGADO ${ }^{1}$ \\ Acta Med Port 2014 Mar-Apr;27(2):155-156
}

Palavras-chave: Liderança; Papel do Médico; Médicos; Portugal.

Keywords: Leadership; Physician's Role; Physicians; Portugal; State Medicine.

Os Sistemas de Saúde estão hoje sujeitos a uma enorme pressão sobre os custos. O paradigma ético de que em Saúde não se olha a meios para atingir os fins (a Saúde e bem estar das populações, curar e salvar vidas humanas), foi inexoravelmente substituído pelo paradigma da eficiência (produzir resultados de qualidade com custos controlados).

Esta alteração no modelo ético e social tem na sua génese o exponencial crescimento dos custos na Saúde, a dificuldade em obter receitas (públicas ou privadas) para os acomodar de forma sustentada e o imperativo da universalidade na cobertura de cuidados, ou seja o acesso equitativo para todos os cidadãos.

Neste novo cenário, sobressaem as questões da Gestão cuja finalidade é utilizar racionalmente os recursos disponíveis, maximizando a criação de valor para os doentes e para a sociedade. ${ }^{1,2}$

$E$ é neste novo contexto que assume particular relevância a gestão operacional dos serviços médicos, quer na perspectiva ambulatória, quer na componente de internamento hospitalar.

É hoje comum nos hospitais que as Direções de Serviços ou dos Departamentos ou 'Área de Negócio', incluam gestores profissionais, como intervenientes relevantes na assessoria técnica das principais decisões e no acompanhamento e avaliação da performance clínica. ${ }^{3}$

Mas cabe aos médicos assumir a liderança operacional dos seus serviços, numa perspetiva simultaneamente clínica e de gestão. E é neste ponto que as mudanças de paradigma exigem uma nova cultura médica, uma nova atitude e novas competências. ${ }^{4}$

No passado, a boa gestão hospitalar era reconhecida, principalmente pelos médicos, pela capacidade de dotar os serviços de bons e mais recursos, não regateando meios e dando boas condições de trabalho.

Um serviço bem gerido era reconhecido pela dimensão e aprumo das suas instalações, pela grandeza e variedade da sua tecnologia, pelo número de camas, pelo número de médicos ou enfermeiros, pelo número de internos, etc.

Atualmente, a perspectiva é diferente: a boa gestão mede-se por resultados clínicos, de qualidade, eficientes,

1. Diretor-Geral. IASIST Portugal Lda. Lisboa. Portugal.

Recebido: 16 de Abril de 2014 - Aceite: 22 de Abril 2014 | Copyright @ Ordem dos Médicos 2014 realizados com produtividade adequada e de fácil acesso para os doentes. ${ }^{5}$

O bom serviço reconhece-se hoje na comparação dos seus procedimentos e dos seus resultados, dos tempos de internamento, das complicações, das readmissões, da mortalidade, dos tempos de espera, da pontualidade, da sua complexidade e da gravidade dos seus doentes, face a hospitais e serviços similares. Mas também na comparação da sua eficiência técnica, no uso de medicamentos ou de meios complementares de diagnóstico, na produtividade dos blocos operatórios ou de equipamentos pesados, etc.

Esta nova perspectiva remete-nos para o conceito (dificilmente traduzível para português), de Accountability que, em termos simples significa a capacidade de um dirigente demonstrar de forma objetiva e controlável como utilizou os recursos sobre os quais tinha a responsabilidade (instalações, equipamentos, pessoas, consumos correntes, etc.) ao longo de um determinado período de tempo.

Hoje, em todos os países desenvolvidos, as grandes instituições hospitalares preparam a sua atividade de curto, médio e longo prazos, com base em previsões de desempenho quantitativo e qualitativo e negoceiam com os financiadores, volume, qualidade e tempo de acesso aos cuidados que contratualizam, por um determinado preço.

Isto pressupõe um alinhamento, constante e harmonioso, entre as Administrações e os níveis operacionais, no sentido de trabalharem concertadamente para os mesmos objetivos, para as metas contratualizadas e sob a mesma visão estratégica. ${ }^{6}$

Esta nova responsabilidade aumenta o protagonismo dos médicos, apreciados não apenas pelas suas qualidades técnicas e pelo seu prestígio, mas também pelas suas capacidades de gestão de recursos, em que os resultados são sempre confrontados com os meios utilizados para os obter, num compromisso assumido de metas a atingir.

São novos desafios que pressupõem novas competências. Não se pretende transformar um médico num gestor mas acrescentar-Ihe conhecimentos, em matérias de organização e eficiência, na liderança dos seus serviços.

Estranho que, apesar de reconhecidas por todos como ferramentas indispensáveis para o desempenho da gover- 
nação clínica, a formação médica, pré e pós-graduada, não incorpore sistematicamente matérias de gestão, como se verifica hoje nos curricula académicos de muitos países.

As universidades portuguesas, em colaboração com a

\section{REFERÊNCIAS}

1. Porter M, Lee TH. The strategy that will fix health care. Harvard Business Review. 2013. [Consultado 2014 Apr 15]. Disponível em: http:// hbr.org/2013/10/the-strategy-that-will-fix-health-care/ar/1.

2. Kim Y, Farmer P, Porter M. Redefining global health - care delivery. Lancet. 2013;382:1060-9.

3. Sutherland K, Dawson S. Power and quality improvement in the new NHS: the roles of doctors and managers. Qual Health Care.
Ordem dos Médicos deveriam colocar este tema como prioridade na revisão curricular dos cursos de Medicina. Ganhariam os profissionais, os serviços, os doentes e o país.

1998;7:S16-23.

4. Atun RA. Doctors and managers need to speak a common language. BMJ. 2003;326:655.

5. Donaldson L, Gray JA. Clinical governance: a quality duty for health organisations. Qual Health Care. 1998;7:S37-44.

6. Edwards N. Doctors and managers: building a new relationship. Clin Med. 2005;5:577-9. 


\section{Os Médicos e a Gestão}

Acta Med Port 2014:27:155-156

Publicado pela Acta Médica Portuguesa, a Revista Científica da Ordem dos Médicos

Av. Almirante Gago Coutinho, 151

1749-084 Lisboa, Portugal.

Tel: +351 218428215

E-mail: submissao@actamedicaportuguesa.com

www.actamedicaportuguesa.com

ISSN:0870-399X | e-ISSN: 1646-0758

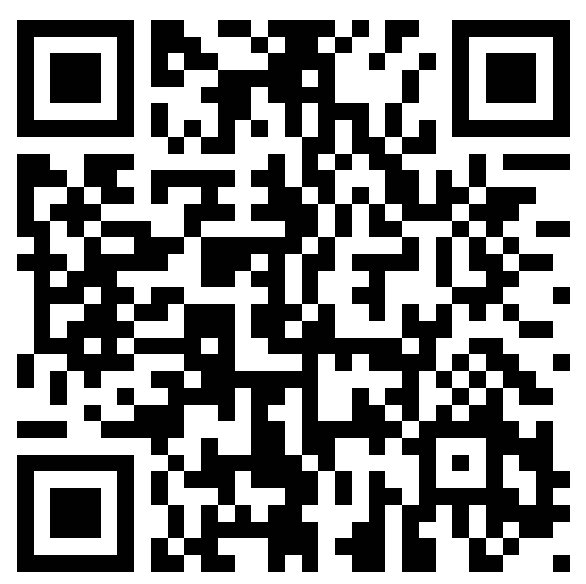

